\title{
Эмпирическая макроэкономика
}

\author{
Б.И. Алехин \\ СКОЛЬКО ДЕНЕГ \\ НУЖНО РОССИЯНАМ И ЗАЧЕМ
}

Цель статьи - публикация результатов эмпирического анализа спроса на деньги в современной России. Для этого была определена теоретическая основа уравнения спроса на деньги, подобраны функциональная форма уравнения и данные для его оценивания, выявлен наилучший состав регрессоров в уравнении, сформулирована эконометрическая методология, выполнены тесты на стационарность и коинтеграцию переменных, оценена модель коррекции ошибок и протестирована стабильность функции спроса на деньги.

Ключевые слова: спрос на деньги, коинтеграция, модель коррекции ошибок.

Стабильная функция спроса на деньги - это устойчивая и потому предсказуемая зависимость спроса на деньги от объема трансакций и других макроэкономических величин. Обнаружение стабильной функции спроса на деньги - одна из важных задач, стоящих перед разработчиками денежной политики в тех странах, где центральный банк устанавливает ориентиры для изменения предложения денег ${ }^{1}$. Чтобы эти ориентиры расширяли занятость, стимулировали экономический рост и не провоцировали инфляцию, центральному банку необходимо знать, какую часть своего богатства люди хотят держать в денежной форме. Тогда предложение денег будет соответствовать спросу на них, и экономика пойдет курсом, начертанным центральным банком. Там, где используется иной денежно-политический режим, стабильная функция спроса на деньги является существенным подспорьем в аналитике трансмиссионного механизма денежной политики.

(С Алехин Б.И., 2015 
Интерес к изучению спроса на деньги возрос во всем мире в 1970-х гг. после «провала уравнения» (equation's failure) в США, Канаде и некоторых других развитых странах. В США, например, одним из нескольких инструментов, используемых Федеральной резервной системой (ФРС) для установки ориентиров по денежной массе, было уравнение регрессии денежного агрегата M1 по общим расходам и другим важным переменным. Варьируя темп изменения M1 и используя уравнение вкупе с другими инструментами, ФРС могла предсказывать уровни этих переменных и таким образом выбирать темп, в наибольшей степени отвечающий целям страны в области экономики.

Уравнение, однако, не отличалось надежностью и никогда не было совершенным предсказателем спроса на деньги. В середине 1970-х гг. оно выдало прогноз, превышающий фактические уровни на удивительно крупную сумму. С тех пор ошибки прогноза только увеличивались. Уравнение оказалось статистически нестабильным: историческая связь спроса на деньги с его детерминантами, выраженная коэффициентами регрессии, стала непредсказуемо меняться во времениㄹ․

Много усилий было потрачено на поиски уравнения стабильнее «провального». Исследователи старались отыскать переменные, имеющие теснейшую связь со спросом на деньги. ФРС, Банк Канады и некоторые другие регуляторы расширяли определение денег, отдавая должное быстрому росту финансовых активов за пределами М1. Однако эти усилия не привели к существенному улучшению прогностической способности уравнения.

«Провалу уравнения» можно не удивляться, если вспомнить о теории, которая стоит за уравнением. Уравнение не учитывает, как люди реально решают, сколько денег держать под рукой и особенно во время быстрых перемен в окружающей их финансовой среде. Теория предполагает, что уравнение не сможет точно предсказывать спрос на деньги, пока эта среда не стабилизируется. А она продолжает меняться и, похоже, все быстрее. Что еще важнее для центрального банка, так это откровения теории о бесполезности уравнения в качестве денежно-политического инструмента. Надо забыть об уравнении и заняться обновлением самого подхода к моделированию поведения экономических агентов ${ }^{3}$.

«Провал уравнения» вызвал не только «цунами» эмпирических работ в США, но и волну интереса к изучению спроса на деньги в развивающихся странах. Там эмпирический анализ натыкался на те же проблемы традиционной спецификации - автокорреляцию, крупные ошибки прогноза, неверные знаки и статистическую не- 
значимость коэффициентов регрессии. В 2000-х гг. волна интереса докатилась и до России. В 2010 г. была опубликована брошюра сотрудников Института экономической политики им. Е.Т. Гайдара о моделировании спроса на деньги в России, где среди прочего есть детальный обзор зарубежной литературы

Целью данной работы является эмпирический анализ спроса на деньги в России с акцентом на качество измерителя издержек владения деньгами и стабильность денежной функции. Для достижения цели были решены следующие задачи:

- определена теоретическая основа уравнения спроса на деньги;

- подобраны функциональная форма уравнения и данные для его оценивания;

- выявлен наилучший состав независимых переменных в уравнении с точки зрения мультиколлинеарности;

- сформулирована эконометрическая методология;

- переменные проверены на наличие единичного корня;

- проведен коинтеграционный анализ переменных;

- оценена модель коррекции регрессионных остатков;

- протестирована стабильность функции спроса на деньги.

\section{Теоретический фундамент}

За долгие десятилетия изучения спроса на деньги в мировой литературе сложились устойчивые тенденции и предпочтения в отношении некоторых вопросов, с которыми сталкиваются исследователи. Один консенсус, который можно почерпнуть из литературы, заключается в том, что эмпирическая работа мотивируется комбинацией теорий 5 . Данная работа мотивирована кейнсианской теорией спроса на деньги, которая является комбинацией теории предпочтения ликвидности и количественной теории денег.

Спрос на деньги связан со способностью денег служить средством обмена и хранилищем стоимости. Из этих функций Кейнс вывел три мотива предпочтения ликвидности:

- трансакционный мотив. Имея деньги под рукой, можно пережить «кассовые разрывы», возникающие из-за того, что поступление дохода по времени или сумме не совпадает с запланированными расходами;

- мотив предосторожности. Экономические агенты стремятся иметь резервуар покупательной способности на случай непредвиденных расходов. Деньги под рукой позволяют избежать «болезни неликвидности или виселицы банкротства»; 
- спекулятивный мотив. Экономические агенты стремятся держать богатство в денежной форме, ожидая, что уровень процента на альтернативные активы повысится и возникнет угроза потери капитала.

«Спрос на деньги, соответствующий первым двум мотивам, писал Кейнс, - реагирует разве что на изменения общей экономической активности и уровня доходов; тогда как агрегатный спрос на деньги, соответствующий спекулятивному мотиву, демонстрирует неизменную чувствительность к постепенным колебаниям уровня процента» ${ }^{7}$. Кейнсианская модель спроса на деньги имеет следующий вид:

$$
M=M_{1}+M_{2}=L_{1}(Y)+L_{2}(r)=L(Y, r)
$$

где $M_{1}$ - реальные кассовые остатки, соответствующие трансакционному мотиву и мотиву предосторожности;

$M_{2}$ - реальные кассовые остатки, соответствующие спекулятивному мотиву;

$L_{1}$ - функция ликвидности, соотносящая $M_{1}$ с реальным доходом $Y$;

$L_{2}$ - функция ликвидности, соотносящая $M_{2}$ с уровнем процента $r^{8}$.

В количественной теории денег спрос на деньги увязан с доходом, но в ней не нашлось места для уровня процента. Подключение предпочтения ликвидности (спекулятивного мотива) к объяснению спроса на деньги - отдельный значительный вклад Кейнса. «Именно Кейнс привел неоспоримые доводы в пользу включения уровня процента в модель спроса на деньги и учета в макроэкономическом анализе чувствительности агрегатного спроса на деньги к предпочтению ликвидности» ${ }^{9},-$ отмечает Шрирам в обзоре работ по спросу на деньги.

\section{Выводы из эмпирической литературы}

Переходя к эмпирическому анализу, отметим еще несколько вытекающих из литературы заключений:

- эмпирические исследования обычно стартуют с предположения о том, что шанс получить стабильную функцию спроса на деньги выше, если использовать как можно меньше переменных, связывающих деньги с реальным сектором. Исследователи в своем большинстве заключают, что главными, 
если не исчерпывающими детерминантами спроса на деньги являются объем трансакций и издержки владения деньгами;

- эмпирическая модель должна быть «скупой» на математику, т. е. использовать минимум математических терминов для описания реальной ситуации;

- выбор функциональной формы модели и данных для измерения переменных - вопрос эмпирический;

- эконометрическая методология так же важна, как спецификация модели. С адекватно специфицированными моделью и методологией, такой как коинтеграция плюс модель коррекции ошибок, выше шанс обнаружить стабильную функцию спроса на деньги с «вменяемыми» оценками параметров. Шрирам назвал модель коррекции ошибок «рабочей лошадкой» в эмпирических исследованиях спроса на деньги ${ }^{10}$;

- многочисленные страновые исследования показывают, что реальные кассовые остатки коинтегрированы с традиционными аргументами функции. Чтобы использовать не только долгосрочную равновесную связь остатков с аргументами, но и их краткосрочные взаимоотношения, следует оценить динамический процесс восстановления равновесия;

- поступает все больше эмпирических свидетельств в пользу растущего зарубежного влияния на спрос на деньги по мере втягивания местных финансовых рынков в мировую экономику и перехода некоторых государств к плавающему курсу национальной валюты.

\section{Уравнение спроса на деньги}

\section{Спецификация}

Теория оставляет выбор функциональной формы авторам эмпирических работ, а авторы в своем большинстве предпочитают логарифмическую (log-log), логарифмически-линейную (log-linear) или линейно-логарифмическую (linear-log) формы ${ }^{11}$. В данной работе спецификация модели (1) - это линейное уравнение множественной регрессии с логарифмированными переменными:

$$
m_{t}=\alpha_{0}+\alpha_{1} y_{t}+\alpha_{2} r_{t}+\varepsilon_{t},
$$

где $m_{t}$ - логарифм реального спроса на деньги,

$y_{t}$ - логарифм реального дохода,

$r_{t}-$ логарифм уровня процента. 
Логарифмирование - привычный выход из ситуации, когда отношения между зависимой и независимыми переменными (регрессорами) нелинейны. Оно удаляет из данных мультипликативные эффекты, приближает распределение переменных к нормальному, снижает гетероскедастичность (стабилизирует вариацию), позволяя линейному уравнению (2) точнее описывать предполагаемую зависимость.

$\alpha_{0}$ - это свободный член (константа), а $\alpha_{1}$ и $\alpha_{2}-$ коэффициенты при регрессорах $y$ и $r$. В логарифмической модели интерпретировать коэффициенты следует как ожидаемое процентное изменение зависимой переменной в ответ на изменение регрессора на какой-то процент. В эконометрике такая связь обычно называется эластичной, а коэффициенты - эластичностями.

Теория подсказывает, что $\alpha_{1}>0$ и $\alpha_{2}<0$. Чем выше доход при неизменном уровне процента и цен, тем больше трансакций совершают экономические агенты и тем, следовательно, больше денег им требуется для расчетов. Чем ниже ожидаемый уровень процента при неизменном реальном доходе и уровне цен, тем привлекательнее деньги как хранилище богатства и тем, следовательно, больше спрос на них.

\section{Даннье для оценивания уравнения}

Для измерения спроса на деньги исследователи используют, главным образом, официальные денежные агрегаты M1 и M2. Со временем М2 приобрел большую популярность, чем М1, поскольку он, по мнению некоторых авторов, выдает стабильную денежную функцию, позволяет лучше оценить долгосрочные последствия изменений в денежной политике, имеет более устойчивую связь с доходом, хотя и не так плотно контролируется центральным банком, как M12. $^{12}$ В данной работе спрос на деньги измеряется реальным M2 - частным от деления номинального М2 на дефлятор ВВП. Этот агрегат складывается из наличных рублей вне банковской системы, рублевых вкладов до востребования и рублевых срочных депозитов (табл. 1). 


\section{Структура денежного агрегата М2 по состоянию на 01.05.2015}

\begin{tabular}{|l|c|}
\hline \multicolumn{1}{|c|}{ Компонент денежной массы } & Доля, \% \\
\hline \multicolumn{1}{|c|}{ Денежный агрегат М0 } & 20,6 \\
\hline Наличные деньги вне банковской системы & 8,1 \\
\hline \multicolumn{1}{|c|}{ Денежный агрегат M1: M0 плюс } & 17,4 \\
\hline $\begin{array}{l}\text { переводные депозиты населения } \\
\text { переводные депозиты нефинансовых и финансовых } \\
\text { (кроме кредитных) организаций }\end{array}$ & 36,0 \\
\hline \multicolumn{2}{|c|}{ Денежный агрегат М2: М1 плюс } \\
\hline $\begin{array}{l}\text { срочные депозиты населения } \\
\text { срочные депозиты нефинансовых и финансовых } \\
\text { (кроме кредитных) организаций }\end{array}$ & 17,8 \\
\hline Итого & 100,0 \\
\hline
\end{tabular}

Источник: Центральный банк Российской Федерации. Статистика. http://www.cbr.ru/statistics/?PrtId=ms\&pid=dkfs\&sid=dm

Для измерения дохода, характеризующего объем трансакций, чаще используется ВВП, хотя при этом не учитываются трансферы, промежуточные трансакции, финансовые активы, зато учитываются вмененные величины, за которыми нет конечных трансакций. Некоторые авторы вместо ВВП используют валовой национальный доход, валовые национальные расходы, располагаемый доход, частные расходы. В отдельных работах фигурируют «денежноемкие» компоненты ВВП и трансакционные величины типа объема промышленного производства. В данной работе доход представлен реальным ВВП, так что трансакции за счет М2 ограничены покупками вновь произведенных материальных благ, включая элементы реального капитала.

В уравнении (2) первоначально фигурировал целый вектор издержек владения деньгами, что не противоречит теории, а уточ- 
няет ее, поскольку Кейнс не сводил уровень процента к какой-то одной ставке, а видел за его изменениями «изменения цен облигаций и прочих долгов разной длительности» ${ }^{13}$. Вот элементы этого вектора:

- ставка процента по срочным депозитам М2. Поскольку в данной работе спрос на деньги представлен М2, состоящим более чем наполовину из срочных депозитов с их вполне рыночной доходностью, нельзя сказать, что доходность М2 равна нулю;

- краткосрочная, среднесрочная, долгосрочная и простая средняя доходность облигаций федерального займа (ОФЗ) на вторичном рынке. Если доходность М2 - доходность собственно денег, то доходность ОФЗ - доходность внешняя, за пределами М2. Ею можно измерить издержки владения деньгами (упущенную выгоду от пристрастия к деньгам);

- индекс потребительских иен (ИПЦ). Он характеризует издержки владения деньгами относительно цен потребительских товаров. Чем выше ожидаемая инфляция, привычным мерилом которой является ИПЦ, тем сильнее боязнь обесценения денег и тем больше денег уходит из M2 на покупку потребительских товаров;

- рыночный курс обмена рубля на доллары США. Включение в уравнение (2) этого вида внешней доходности связано с тем, что для россиян, их финансовых посредников и Банка России американская валюта играет роль хранилища стоимости и предмета спекуляций. Доллар США и прочая иностранная валюта не включены в М2, и чем выше рублевая стоимость доллара, тем больше рублей уходит из М2 на покупку американской валюты.

С денежно-политической и статистической точек зрения наиболее удобными являются квартальные данные. Федеральная служба государственной статистики России публикует реальный ВВП и ИПЦ в разбивке по кварталам. Остальные данные публикуются Банком России в ином временном срезе, и их пришлось усреднять за кварталы ${ }^{14}$. Самым «молодым» временным рядом является доходность ОФЗ, позднее других обновляется ВBП. Эти два ряда и определили период наблюдения: c IV кв. 2000 г. по I кв. 2015 г. (2000:4-2015:1), т. е. 58 среднеквартальных наблюдений $(\mathrm{T}=58)$. Из всех рядов только М2 и ВВП обнаружили признаки квартальной сезонности и были очищены от нее. Принятый в данной работе доверительный интервал равен $95 \%(\alpha=0,05)$. 
Изучая графики и описательную статистику переменных, можно заметить, во-первых, сходство описаний реальных М2 и ВВП, указывающее на наличие неких сходных трендов в их рядах, и, во-вторых, значительную асимметрию и эксцесс, указывающие на проблему с нормальным распределением всех переменных. В результате логарифмирования распределение реального M2 и всех регрессоров, кроме реального ВВП и ИПЦ, приблизилось к нормальному. Однако ни одна из этих переменных не прошла тест Шапиро-Уилка на нормальность. Ряды экономической динамики редко обладают этим свойством. Распределение реального ВВП стало чуть менее нормальным, а распределение ИПЦ не изменилось.

\section{Избыточные регрессоры}

Подготовив данные для оценивания уравнения (2), мы первым делом произвели «чистку» рядов с целью эмпирического обнаружения наилучшего показателя издержек владения деньгами. Из первых разностей $(\Delta)$ переменных была составлена вспомогательная регрессия, которая после оценивания методом наименьших квадратов (МНК) подверглась тесту на избыточность регрессоров. Нулевая гипотеза $\left(H_{0}\right)$ теста: параметры регрессии равны нулю. Шесть регрессоров оказались избыточными с точки зрения мультиколлинеарности (табл. 2).

Мультиколлинеарность оценивалась методом инфляционных факторов (variance inflation factors - VIF):

$$
V I F_{j}=1 /\left(1-R_{j}^{2}\right)
$$

где $R_{j}^{2}$ - коэффициент множественной корреляции регрессора $j$ и других регрессоров.

Минимальное возможное значение VIF равно 1. Значения больше 10 могут указывать на наличие мультиколлинеарности. Как видим, после удаления избыточных переменных мультиколлинеарность практически исчезла (табл. 2). 
Оценка мультиколлинеарности

\begin{tabular}{|l|c|c|c|}
\hline \multicolumn{1}{|c|}{$\begin{array}{c}\text { Регрессор } \\
\text { в первых разностях }\end{array}$} & p & $\begin{array}{c}\text { VIF } \\
\text { до удаления } \\
\text { избыточных } \\
\text { переменных }\end{array}$ & $\begin{array}{c}\text { VIF } \\
\text { после удаления } \\
\text { избыточных } \\
\text { переменных }\end{array}$ \\
\hline Реальный ВВП & 0,000 & 1,438 & 1,077 \\
\hline $\begin{array}{l}\text { Ставка процента } \\
\text { по срочным депозитам М2 }\end{array}$ & 0,785 & 2,182 & - \\
\hline $\begin{array}{l}\text { Краткосрочная } \\
\text { доходность ОФ3 }\end{array}$ & 0,366 & 37,852 & - \\
\hline $\begin{array}{l}\text { Среднесрочная } \\
\text { доходность ОФЗ }\end{array}$ & 0,120 & 15,644 & 1,077 \\
\hline $\begin{array}{l}\text { Долгосрочная } \\
\text { доходность ОФ3 }\end{array}$ & 0,009 & 14,696 & - \\
\hline $\begin{array}{l}\text { Простая средняя } \\
\text { доходность ОФ3 }\end{array}$ & 0,193 & 128,855 & - \\
\hline $\begin{array}{l}\text { Рыночный курс обмена } \\
\text { рубля на доллар США }\end{array}$ & 0,152 & 1,225 & - \\
\hline ИПЦ & & 2,324 & - \\
\hline
\end{tabular}

Удаление избыточных переменных улучшило все три информационных критерия, по которым обычно судят о качестве регрессии: Акаике, Шварца и Хеннана-Куинна (табл. 3). Чем ниже критерий, тем выше качество регрессии.

Таблица 3

Информационные критерии

\begin{tabular}{|l|c|c|}
\hline \multicolumn{1}{|c|}{ Критерий } & $\begin{array}{c}\text { До удаления } \\
\text { избыточных } \\
\text { переменных }\end{array}$ & $\begin{array}{c}\text { После удаления } \\
\text { избыточных } \\
\text { переменных }\end{array}$ \\
\hline Акаике & $-239,608$ & $-244,085$ \\
Шварца & $-221,220$ & $-237,898$ \\
Хеннана-Куинна & $-232,462$ & $-241,645$ \\
\hline
\end{tabular}


«Чистку» рядов пережили реальный ВВП и долгосрочная доходность ОФЗ, для которых $H_{0}$ была опровергнута. Получилась «скупая» модель. Теперь уровень процента $r$ в уравнении (2) - это логарифм долгосрочной доходности ОФЗ. «Сеянные» таким образом $\Delta y_{t}$ и $\Delta r_{t}$ имеют ожидаемые знаки, экономически весомы и статистически значимы (табл. 4). Критерий Фишера $F(2,54)=60,448$ и $P(F)=0,000$, что указывает на значимость всей регрессии. Статистика Дарбина-Уотсона $(D W)=1,788$. Гипотеза о положительной автокорреляции остатков не подтвердилась. Исправленный коэффициент детерминации $R^{2}=0,680$, что намного меньше $D W$. Так должно быть у подлинной, а не мнимой регрессии.

Таблица 4

Вспомогательная регрессия

после удаления избыточных переменных

\begin{tabular}{|c|c|c|c|c|}
\hline \multicolumn{5}{|c|}{$\begin{array}{l}\text { Метод оценивания - МНК } \\
\text { Период оценивания - 2001:4-2015:1 }(T=57) \\
\text { Зависимая переменная } \Delta m_{t}\end{array}$} \\
\hline Регрессор & Коэффициент & $\begin{array}{c}\text { Стандартная } \\
\text { ошибка }\end{array}$ & $t$-статистика & $p$ \\
\hline Константа & 0,009 & 0,007 & 1,377 & 0,174 \\
\hline$\Delta y_{t}$ & 1,242 & 0,130 & 9,539 & 0,000 \\
\hline$\Delta r_{t}$ & $-0,115$ & 0,042 & $-2,726$ & 0,009 \\
\hline
\end{tabular}

\section{Эконометрическая методология}

\section{Проблема единичного корня}

В 1959 г. Фридман писал, что «правильная» функция спроса на деньги предполагает стационарное долговременное равновесие реальных кассовых остатков, реального дохода и издержек владения деньгами ${ }^{15}$. Однако ряды экономической динамики обычно нестационарны в уровнях, но стационарны в первых разностях. Такие ряды именуются интегрированными (I) порядка 1 и обозначаются I(1). У них отсутствуют постоянное среднее, постоянная вариация или оба этих свойства.

Нестационарность оборачивается несколькими эконометрическими проблемами, главная из которых - мнимые регрессии. 
«В литературе о прикладной эконометрике, - отмечали Грэнджер и Ньюболд в 1973 г., - часто сообщается о временных рядах с очень высокой степенью подгонки, измеренной коэффициентом множественной корреляции $R^{2} \ldots$ и очень низкой статистикой Дарбина-Уотсона $(d)$... Самый экстремальный пример, с которым мы столкнулись, это уравнение с $R^{2}=0,990$ и $d=0,093$. Мы предлагаем считать всецело ложными гораздо менее экстремальные регрессии... Высокий $R^{2}$ при низкой $d$, указывающей на сильную автокорреляцию остатков, не свидетельствует о подлинной связи» ${ }^{16}$.

Если цель исследования - выявление долговременного равновесия или предсказание будущего, то ряды должны быть стационарными (стабильными, устойчивыми). Такие ряды именуются интегрированными (I) порядка 0 и обозначаются I(0). В 1973 г. Грэнджер и Ньюболд рекомендовали за неимением лучшего использовать в регрессионном анализе разности переменных, так как переход с уровней на разности превращает ряд из $\mathrm{I}(1)$ в $\mathrm{I}(0)^{17}$.

Мы воспользовались этой рекомендацией при тестировании избыточности регрессоров. Назвать вспомогательную регрессию (табл. 4) мнимой после удаления избыточных регрессов нельзя: $R^{2}=0,680$ и $D W=1,788$. Обсуждением ее можно было бы и закончить данное исследование. Но остается другая проблема: регрессия не отражает предсказания теории о стационарном долговременном равновесии.

Нестационарность проистекает из нескольких источников, главным из которых является единичный корень. Простейшая модель, которая может содержать единичный корень, это модель AR(1):

$$
Y_{t}=\varphi Y_{t-1}+\varepsilon_{t}
$$

где $\varepsilon_{t}-$ белый шум с нулевым средним и постоянной вариацией.

Если $\varphi=1$, то $Y_{t}$ (в уровнях) становится нестационарным процессом, и возникает проблема единичного корня. Если $\varphi<1$, то $Y_{t}$ стационарен. Проблему единичного корня можно решить, взяв последовательную разность и тем самым заменив $\varphi=1$ на $\varphi<1$.

В данной работе проверка на наличие единичного корня выполнялась при помощи расширенного теста Дики-Фуллера. В простейшей версии тест представляет собой оценку регрессии (3), чтобы проверить, $\varphi=1$ или нет. Но делается еще пара преобразований, чтобы получить удобную гипотезу $H_{0}$ :

$$
Y_{t}-Y_{t-1}=(\varphi-1) Y_{t-1}+\varepsilon_{t}
$$




$$
\Delta Y_{t}=\delta Y_{t-1}+\varepsilon_{t}
$$

где $\delta=(\varphi-1)$.

На практике оценивается уравнение (5) и тестируется $H_{0}$ : $\delta=0$ против альтернативной гипотезы $\left(H_{0}\right): \delta \neq 0$. Если $\delta=0$, то $\varphi=1$. Значит, имеет место единичный корень и ряд признается нестационарным.

\section{Тест на коинтегращию}

В 1987 г. Грэнджер и Энгл предложили исследователям «лучшее» взамен хорошего (анализа разностей) - коинтеграцию плюс модель коррекции ошибок ${ }^{18}$. Если каждая переменная - I(1) и существует хотя бы одна их линейная комбинация I(0), то они называются коинтегрированными, а линейная комбинация I(0) - коинтегрирующим уравнением, которое можно интерпретировать как эконометрический «снимок» стабильного долгосрочного равновесия. В данном случае коинтегрирующее уравнение это уравнение (2).

Любая теория равновесия, использующая ряды I(1), требует, чтобы существовала их линейная комбинация I(0). Иначе любая потеря равновесия будет не временной, а «раз и навсегда». В нашем случае неспособность обнаружить коинтеграцию рядов I(1) означает, что долгосрочный спрос на деньги отсутствует в любом сколь-нибудь значимом смысле этих слов. Коинтеграция - это эконометрическая концепция, имитирующая пребывание переменных I(1) в стабильном долгосрочном равновесии ${ }^{19}$.

Чтобы обнаружить коинтеграцию по Грэнджеру-Энглу, необходимо получить МНК-оценку уравнения (2) и проверить остатки регрессии на наличие единичного корня. Если остатки - I(0), то переменные коинтегрированы, а МНК-оценка суперсостоятельна, так как «сходится к истинному значению быстрее, чем в случае классической регрессии» ${ }^{20}$.

Еще один ставший очень популярным тест на коинтеграцию предложил в 1988 г. Йохансен ${ }^{21}$. Это тест второго поколения, так как коинтегрированные переменные выводятся прямо из оценки методом максимального правдоподобия, а не из «старомодной» МНК-оценки, как у Грэнджера-Энгла. Тест Йохансена проверяет след матрицы и ее максимальное собственное значение. Для проверки следа матрицы $H_{0}: r>0$, а $H_{a}: r=0$, где $r$ - число рангов коинтеграции. Для проверки максимального собственного значения $H_{0}$ : $r=r$, a $H_{a}: r+1$.

В соответствии с МНК тест Грэнджера-Энгла требует назначения каждой переменной $(m, y, r)$ на роль зависимой переменной, 
но не требует оценки всех (трех) коинтеграционных уравнений. Достаточно оценить одно уравнение, например, уравнение (2), и допускается, что тот же результат даст оценка остальных (двух) уравнений (с $y$ и $r$ в левой части уравнения). На практике это допущение выполняется не всегда: одно уравнение может показать, что переменные коинтегрированы, а другое или другие - что переменные не коинтегрированы. Тест Йохансена обходит эту проблему, так как он основан на методе максимального правдоподобия.

Оба теста нестабильны. Один тест может обнаружить коинтеграцию там, где другой ее не увидит. Эконометрики рекомендуют применять тест Йохансена, так как он способен обнаружить более одной коинтеграционной связи, когда переменных более двух, и показывает сложное взаимодействие причинности и структуры, позволяющее лучше понять «систему».

\section{Модель коррекции ошибок}

Органичным продолжением теста на коинтеграцию является расчет модели коррекции ошибок (МКО). МКО можно определить как динамичную модель, в которой движение переменной в текущем периоде обусловлено отклонением от долгосрочного равновесия в предыдущем периоде. Когда переменные коинтегрированы и любой шок вызывает потерю (ошибку) равновесия, срабатывает хорошо определенный процесс краткосрочной динамической коррекции, возвращающий «систему» в равновесие ${ }^{22}$. Часть ошибки равновесия в предыдущем периоде исправляется в текущем и, возможно, будущих периодах. Чем меньше требуется периодов для достижения (нового) равновесия, тем эффективнее механизм коррекции ошибок. Главное достоинство МКО в том, что она оставляет спецификацию долгосрочного равновесия на попечение экономической теории, а краткосрочную динамику извлекает из данных 23.

Чтобы получить МКО в нашем случае, надо к вспомогательному уравнению (табл. 4), присоединить остатки $\hat{u}$ коинтеграционного уравнения (2) с лагом в один период:

$$
\Delta m_{t}=\alpha_{1} \Delta y_{t}+\alpha_{2} \Delta r_{t}-\lambda \hat{u}_{t-1}+\varepsilon_{t}
$$

где $\Delta m_{t}=\alpha_{1} \Delta y_{t}+\alpha_{2} \Delta r_{t}-$ вспомогательное уравнение (константа исключена, так как она фигурирует в уравнение (2);

$\hat{u}_{t-1}=m_{t-1}-\hat{\alpha}_{0}-\hat{\alpha}_{1} y_{t-1}-\hat{\alpha}_{2} r_{t-1}-$ остатки уравнения (2), измеряющие «расстояние», на которое зависимая переменная отклонилась от равновесия с регрессорами в предыдущем периоде; 
$\lambda$ - коэффициент коррекции остатков, измеряющий скорость достижения нового равновесия в последующих периодах.

Например, если $\lambda=-0,25$, то разность между расчетным и равновесным значениями $m_{t-1}$ сократится (при прочих равных условиях) на одну четверть в периоде $t$ (из-за отрицательного знака $\lambda$ ). Остальные три четверти пути к равновесию будут пройдены в будущих периодах в соответствии с $\lambda$. Срок полного устранения отклонения задается $(1 / \lambda)$, т. е. после $(1 / \lambda)$ периодов достигается равновесие.

\section{Результаты}

\section{Проверка на наличие единичного корня}

Ниже приведены результаты расширенного теста Дики-Фуллера на наличие единичного корня (табл. 5). $H_{0}$ - единичный корень присутствует, а $H_{\text {a }}$ - единичный корень отсутствует. $H_{0}$ не

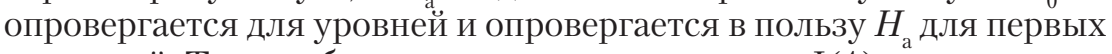
разностей. Таким образом, каждая переменная - I(1), что открывает путь к тесту на коинтеграцию.

\section{Таблица 5}

Результаты расширенного теста Дики-Фуллера на наличие единичного корня (критическое значение статистики теста равно -3,492)

\begin{tabular}{|c|c|c|c|c|c|}
\hline \multirow{2}{*}{ Переменная } & \multicolumn{2}{|c|}{ Уровень } & \multicolumn{2}{|c|}{ Первая разность } & \multirow{2}{*}{ Решение } \\
\cline { 2 - 5 } & $\begin{array}{c}\text { статистика } \\
\text { теста }\end{array}$ & $p$ & $\begin{array}{c}\text { статистика } \\
\text { теста }\end{array}$ & $p$ & \\
\hline$m^{*}$ & $-0,198$ & 0,992 & $-6,585$ & 0,000 & $\mathrm{I}(1)$ \\
\hline$y^{*}$ & $-0,332$ & 0,988 & $-7,012$ & 0,000 & $\mathrm{I}(1)$ \\
\hline$r^{*}$ & $-1,967$ & 0,619 & $-4,602$ & 0,003 & $\mathrm{I}(1)$ \\
\hline$\hat{u}^{* *}$ & $-4,068$ & 0,000 & - & - & $\mathrm{I}(1)$ \\
\hline
\end{tabular}

* Тест с константой и трендом, включая 1 лаг (максимум 10, критерий Шварца).

** Тест без константы, включая 1 лаг (максимум 10, критерий Шварца). 


\section{Тест на коинтеграцию}

Тест Йохансена по критерию максимального собственного значения не обнаружил коинтеграционных связей, тогда как статистика следа матрицы $(42,911)$ статистически значима. Следовательно, $H_{0}$ : $r=0$ отвергнута (табл. 6). Тест обнаружил один ранг коинтеграции.

Таблица 6

Результаты теста Йохансена на коинтеграцию

(модель: ограниченный тренд, неограниченная константа)

\begin{tabular}{|c|c|c|c|}
\hline$H_{0}$ & $H_{\mathrm{a}}$ & Статистика следа матрицы & $p$ \\
\hline$r=0$ & $r=1$ & 42,911 & 0,048 \\
\hline$r \leqslant 1$ & $r=2$ & 20,849 & 0,189 \\
\hline$r \leqslant 2$ & $r=3$ & 5,983 & 0,473 \\
\hline
\end{tabular}

Тест Грэнджера-Энгла был выполнен в два этапа. Сначала была получена МНК-оценка коинтегрирующего уравнения (2):

$$
\begin{gathered}
m_{t}=-3,912+1,478 * y_{t}-0,087 * r_{t} \\
\mathrm{~T}=58, R^{2}=0,998, D W=0,627 .
\end{gathered}
$$

Выведенные из уравнения (7) $t$-уровни интерпретации не подлежат, поскольку уравнение долгосрочное и потому обременено автокорреляцией (из-за неверно специфицированной динамики) и проблемой пропущенных или неучтенных переменных. Так что распределение $t$-уровней неизвестно и нет смысла приводить их здесь. Диагностическое тестирование тоже не имеет смысла. Важен лишь вопрос, остатки $\hat{u}_{t}$ уравнения $(7)-\mathrm{I}(0)$ ?

Затем остатки $\hat{u}_{t}$ были проверены на наличие единичного корня. Расширенный тест Дики-Фуллера опроверг гипотезу о наличии единичного корня (табл. 6). Следовательно, $\hat{u}_{t}-\mathrm{I}(1)$. Поскольку единичный корень обнаружен в каждой переменной, можно заключить, что переменные коинтегрированы. Тест Грэнджера-Энгла принес те же результаты, что и тест Йохансена. Переменные связывает некая нестационарная компонента (долговременная тенденция), отклонения от которой стационарны и колеблются вокруг нуля ${ }^{24}$.

\section{Оченка модели коррекции ошибок}

Наконец, присоединим остатки $\hat{u}_{t}$ к вспомогательной регрессии (табл. 4) с лагом в один период, чтобы включить механизм 
коррекции ошибок равновесия. Ниже приводятся результаты оценивания МКО (табл. 7). Исправленный $R^{2}=0,897$, т. е. модель объясняет 89,7\% вариации $\Delta m$. Критерий Фишера $F(3,54)=164,107$ и $P(F)=0,000$, что указывает на значимость всей регрессии. $D W=1,513$, что намного больше $R^{2}$. Так и должно быть у подлинной регрессии. Информационные критерии у МКО заметно лучше (меньше), чем у вспомогательной регрессии, что объясняется включением механизма коррекции ошибок.

Коэффициенты регрессии значимы и имеют ожидаемые знаки. $\Delta y$, отражающий трансакционный мотив и предосторожность экономических агентов, оказывает гораздо большее влияние на $\Delta m$, чем «спекулятивный» $\Delta r$. С ростом $\Delta y$ на $1 \% \Delta m$ повышается на $1,39 \%$, а эластичность $\Delta m$ по $\Delta r$ равна лишь $-0,08 \%$. Если забыть о спекулятивном мотиве из-за его экономической «немощи», то МКО будет совсем «скупой» $\left(\Delta m_{t}=\alpha_{0}+\alpha_{1} \Delta y_{t}-\lambda \hat{u}_{t-1}+\varepsilon_{t}\right)$.

Таблица 7

Результаты оценивания модели коррекции ошибок

\begin{tabular}{|c|c|c|c|c|c|}
\hline \multicolumn{6}{|c|}{$\begin{array}{l}\text { Метод оценивания - МНК } \\
\text { Период оценивания - 2001:4-2015:1 }(T=57) \\
\text { Зависимая переменная } \Delta m_{t}\end{array}$} \\
\hline Переменная & \multicolumn{2}{|c|}{ Коэффициент } & $\begin{array}{c}\text { Стандартная } \\
\text { ошибка }\end{array}$ & $t$-статистика & $p$ \\
\hline$\Delta y_{t}$ & \multicolumn{2}{|r|}{1,390} & 0,068 & 20,350 & 0,000 \\
\hline$\Delta r_{t}$ & \multicolumn{2}{|c|}{$-0,082$} & 0,039 & $-23,098$ & 0,041 \\
\hline$\lambda$ & \multicolumn{2}{|c|}{$-0,334$} & 0,098 & $-3,404$ & 0,001 \\
\hline \multicolumn{2}{|c|}{$\begin{array}{l}\text { Среднее зависимой } \\
\text { переменной }\end{array}$} & 0,063 & \multicolumn{2}{|c|}{$\begin{array}{l}\text { Стандартное отклонение } \\
\text { зависимой переменной }\end{array}$} & 0,049 \\
\hline \multicolumn{2}{|c|}{$\begin{array}{l}\text { Сумма квадратов } \\
\text { остатков }\end{array}$} & 0,035 & \multicolumn{2}{|c|}{$\begin{array}{l}\text { Стандартная ошибка } \\
\text { модели }\end{array}$} & 0,026 \\
\hline \multicolumn{2}{|l|}{$R^{2}$} & 0,901 & \multicolumn{2}{|c|}{ Исправленный $R^{2}$} & 0,897 \\
\hline \multicolumn{2}{|l|}{$F(3,53)$} & 164,107 & \multicolumn{2}{|l|}{$P(F)$} & 0,000 \\
\hline \multicolumn{2}{|c|}{ Лог-правдоподобие } & 129,569 & \multicolumn{2}{|c|}{ Критерий Акаике } & $-253,137$ \\
\hline \multicolumn{2}{|c|}{ Критерий Шварца } & $-247,008$ & \multicolumn{2}{|c|}{ Критерий Хеннана-Куинна } & $-250,755$ \\
\hline \multicolumn{2}{|l|}{ Параметр rho } & 0,242 & \multicolumn{2}{|l|}{$D W$} & 1,512 \\
\hline
\end{tabular}

$\lambda$ значима и имеет правильный знак. Значения этого коэффи- 
циента характеризуют скорость достижения равновесия в текущем периоде после потери равновесия в предыдущем периоде и могут быть интерпретированы следующим образом:

- низкие отрицательные значения, стремящиеся к -1: экономические агенты проходят большую часть пути к равновесию уже в текущем периоде;

- крайне низкие отрицательные значения, менее -2: равновесие «зашкаливает»;

- высокие отрицательные значения, стремящиеся к 0: коррекция медленная;

- положительные значения: «система» сошла с равновесной траектории ${ }^{25}$.

Значение -0,334 указывает на умеренную скорость восстановления равновесия в текущем квартале. Нельзя сказать, что это значение стремится к нулю. Но и нельзя сказать, что МКО толкает «систему» К равновесию с высокой скоростью. Остановимся на том, что при прочих неизменных условиях переменные сходятся в коинтегрирующем равновесии со скоростью, примерно равной $1 / 3$ максимальной скорости (-1), при которой равновесие не «зашкаливает». 1/ $\lambda$ показывает число периодов, требуемое для достижения равновесия. Реальному М2 требуется около 3 кварталов, начиная с текущего, чтобы вернуться к своему равновесному значению после изменения реального ВВП в предыдущем квартале.

Пусть реальный ВВП вырос на 5 пунктов. Тогда в текущем квартале реальный М2 сразу подрастет на 1,390 пункта, демонстрируя краткосрочную реакцию на изменение реального ВВП (табл. 7). Но между ними существует и долгосрочная равновесная связь. Тогда в текущем квартале реальный М2 подрастет еще на 1,670 пункта (5*0,334), в следующем квартале - на $1,112\left(3,33^{*} 0,334\right)$ и в заключительном квартале - на 1,112 пункта $(0,741 * 0,334)$. Итак, за неполных 3 квартала экономические агенты, формирующие трансакционный и предупредительный спрос на деньги, нарастят его на 4,913 пункта, чтобы исправить 5\%-ную ошибку равновесия. Остальные 0,087 пункта - отклик на изменение уровня процента.

МКО должна иметь следующие черты классической нормальной линейной регрессионной модели (КНЛРМ):

- модель линейная,

- остатки распределены по нормальному закону,

- серийная корреляция остатков отсутствует,

- число наблюдений не должно превышать число оцениваемых параметров,

- мультиколлинеарность отсутствует. 
Чтобы убедиться в этом, были выполнены диагностические тесты на нормальное распределение остатков, линейную зависимость, гетероскедастичность, автокорреляцию и мультиколлинеарность. Эти тесты были дополнены тестами на адекватность спецификации модели и структурные сдвиги в конкретном квартале. Оказалось, что МКО обладает чертами КНЛРМ, адекватно специфицирована и не имела структурных сдвигов: ни одна $H_{0}$ не опровергнута (табл. 8).

\section{Тестирование стабильности функции спроса на деньги}

Уже то, что МКО успешно прошла тест Чоу, свидетельствует о стабильности формализованной ею функции спроса на деньги. Для углубленной оценки стабильности были выполнены еще два теста на структурный разрыв. Структурный разрыв, т. е. неожиданный пик / провал временного ряда с нарушением критических границ, оборачивается крупными ошибками прогноза и общей ненадежностью модели.

Для теста по критерию кумулятивной суммы (CUSUM) на структурную стабильность $H_{0}$ изменений в параметрах нет. Тестовая статистика Харви-Коллиера $t(53)=0,935$ и $P(t(53)>0,935)=0,354$. Значит, $H_{0}$ не опровергнута. Также был выполнен тест на стабильность параметров по критерию кумулятивной суммы квадратов (CUSUMSQ). Графики CUSUM и CUSUMSQ показывают, что остатки MКО не вышли за границы доверительного интервала, продемонстрировав стабильность параметров МКО на протяжении всего периода наблюдения (рис. 1).
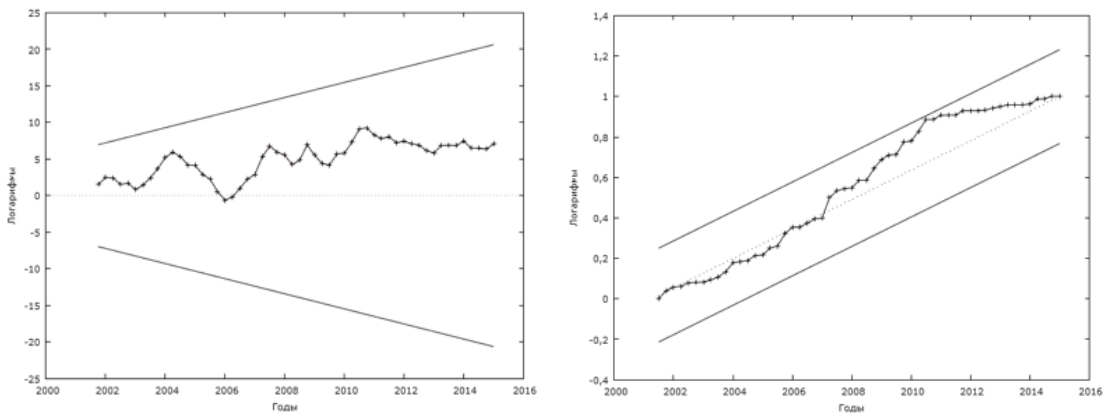

Puc. 1. Графики CUSUM (слева)

и CUSUMSQ для остатков МКО 
$\infty$
0
$\vdots$
$\vdots$
0
0
0

\begin{tabular}{|c|c|c|c|c|c|c|c|c|}
\hline$Z^{\circ}$ & 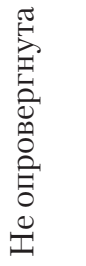 & 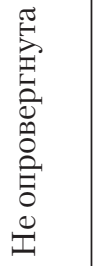 & 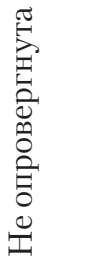 & 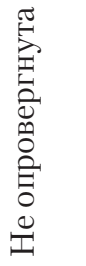 & 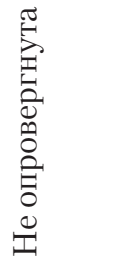 & & 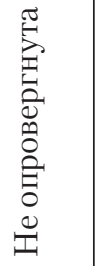 & 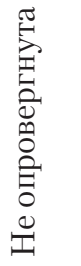 \\
\hline 2 & 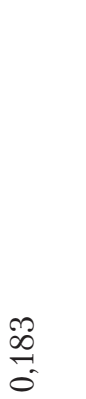 & 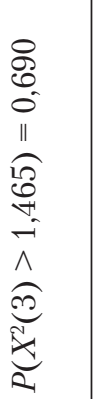 & 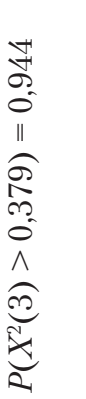 & 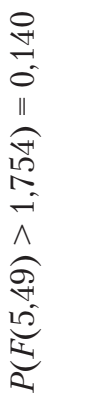 & & & 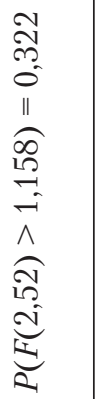 & 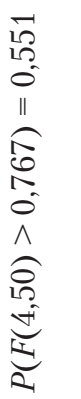 \\
\hline 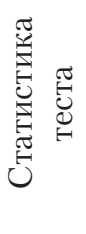 & 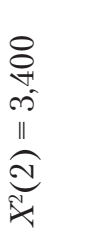 & 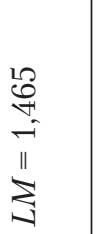 & $\begin{array}{l}\infty \\
m \\
\infty \\
\infty \\
n\end{array}$ & $\frac{12}{11}$ & 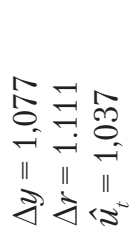 & & 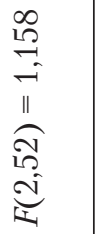 & 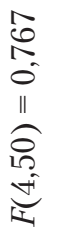 \\
\hline 氖 & 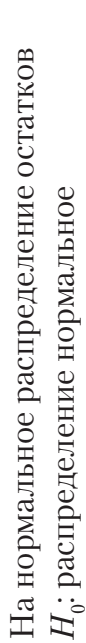 & 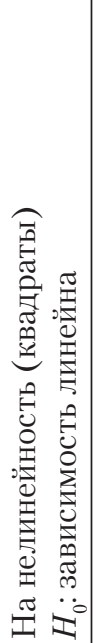 & 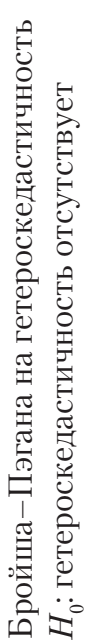 & 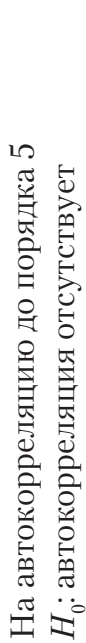 & 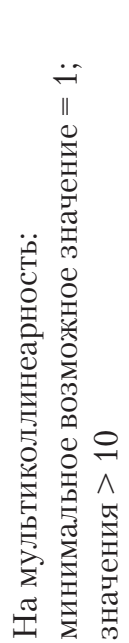 & 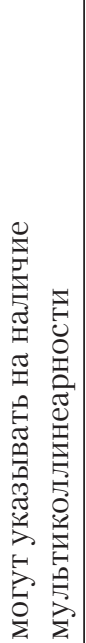 & 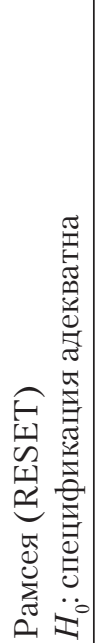 & 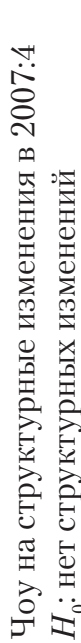 \\
\hline
\end{tabular}


Ниже приведен график динамического прогноза $m$ (реального M2), составленного по МКО (рис. 2). Реальный M2 хорошо вписывается в доверительный интервал. Наиболее популярные оценки точности прогноза - средняя квадратичная ошибка (MSE) и корень из MSE (RMSE). MSE равна 0,015, а RMSE - 0,122. Это свидетельствует о хорошей прогностической способности МКО.

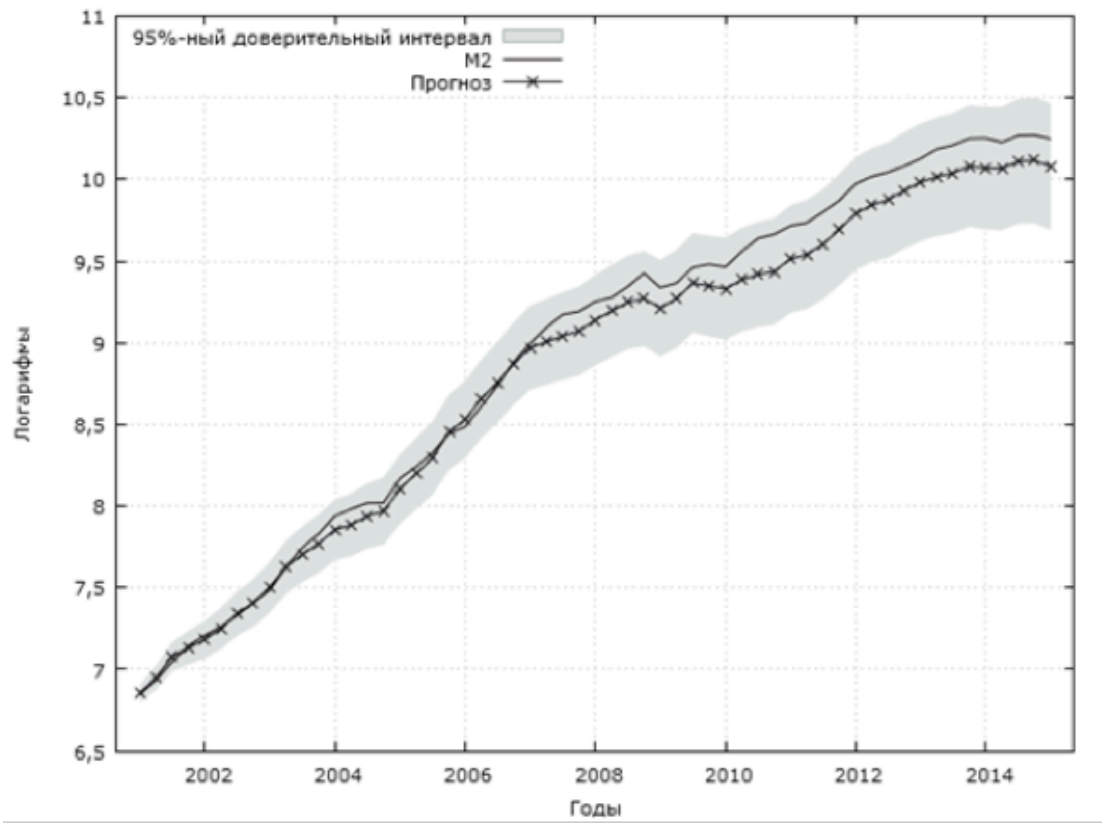

Puc. 2. Прогноз реального M2, извлеченный из МКО

\section{Заключение}

Экономические агенты владеют деньгами, чтобы 1) избегать «кассовых разрывов», 2) обезопасить себя от «болезни неликвидности или виселицы банкротства» и 3) извлекать прибыль из превосходства над рынком в информированности о будущем уровне процента. Эти мотивы предпочтения ликвидности указывают на такую эконометрическую спецификацию, в которой спрос на деньги есть функция дохода и уровня процента как в кейнсианской модели (1). В данной работе спецификацией кейнсианской модели (1) является 
линейное уравнение множественной регрессии с логарифмированными переменными - реальным М2, реальным ВВП и долгосрочной доходностью ОФЗ за 58 кварталов (2000:4-2015:1).

Первоначально в уравнении множественной регрессии фигурировал целый вектор издержек владения деньгами, что обернулось неприемлемой мультиколлинеарностью. Последовательное удаление избыточных переменных позволило покончить с мультиколлинеарностью и получить экономное, «скупое» на математику уравнение (2).

В результате логарифмирования распределение переменных приблизилось к нормальному. Однако ни одна из них не прошла тест Шапиро-Уилка на нормальность. Ряды экономической динамики редко обладают этим свойством.

Визуальный анализ графиков и коррелограмм рядов подвел к мысли о том, что реальный М2 и реальный ВВП имеют сходные тренды и все ряды содержат единичный корень. Расширенный тест Дики-Фуллера не опроверг гипотезу о наличии в рядах единичного корня. Следуя избранной эконометрической методологии, мы провели коинтеграционный анализ.

Тест Йохансена по критерию следа матрицы указал на наличие одного коинтеграционного уравнения. Что касается теста Грэнджера-Энгла, единичный корень не обнаружен в остатках коинтеграционного уравнения, но обнаружен в уровнях каждой переменной, что указывает на их коинтеграцию. Переменные связывает долговременная тенденция, отклонения от которой стационарны и колеблются вокруг нуля. Предсказание теории о наличии стабильного долговременного равновесия подтверждено.

Чтобы использовать не только долгосрочную равновесную связь спроса на деньги с его детерминантами, но и их краткосрочные взаимоотношения, был оценен динамический процесс восстановления равновесия. Результаты оценивания МКО впечатляют. Статистически значимая в целом и в каждом из трех своих регрессоров МКО объясняет почти 90\% вариации реального спроса на деньги. Почти все эти проценты дал реальный доход. Его влияние на реальный спрос на деньги в 17 раз сильнее влияния уровня процента. Экономический вес уровня процента настолько мал, что о спекулятивном мотиве владения деньгами в России можно забыть. Россияне держат деньги под рукой почти исключительно для своевременной и полной оплаты покупок и на случай непредвиденных расходов, которые могут грозить финансовой катастрофой. Оценивание МКО выявило умеренную скорость коррекции ошибок. Реальному М2 требуются текущий 
квартал и еще два ближайших квартала, чтобы вернуться к своему равновесному значению после изменений в правой части МКО в предыдущем квартале.

Информационные критерии у МКО заметно лучше, чем у вспомогательного уравнения первых разностей, которое использовалось для проверки регрессоров на избыточность и не содержало механизма коррекции ошибок. Диагностические тесты показали, что МКО обладает характеристиками КНЛРМ. То, что МКО успешно прошла тест Чоу, свидетельствует о стабильности формализованной ею функции спроса на деньги. Два дополнительных теста на структурный разрыв - CUSUM и CUSUMSQ - показали, что изменений в параметрах МКО не было. Остатки МКО не нарушили критических границ, продемонстрировав тем самым стабильность параметров МКО на протяжении всего периода наблюдения. Стабильная МКО способна выдавать хорошие прогнозы.

Примечания

1 Friedman $M$. The demand for money: some theoretical and empirical results // Journal of Political Economy. 1959. Vol. 67; Laidler D.E.W. The Demand for Money: Theories and Evidence. L.: Harper \& Row, 1977.

2 Duprey J.N. The Search for a Stable Money Demand Equation // Federal Reserve Bank of Minneapolis. Quarterly Review. 1980. Vol. 4. № 3. P. 5. Ibid.

4 Дробышевский С.М., Кузьмичева Г.В., Синельникова-Мурылева Е.В., Трунин П.В. Моделирование спроса на деньги в российской экономике в 1999-2008. М., 2010 (Научные труды ИЭП. № 136Р); Синельникова-Мурылева Е.В. Мировой опыт исследований спроса на деньги и его применение для России // Российский внешнеэкономический вестник. 2011. № 11; Она же. Оценка спроса на деньги в российской экономике с учетом развития банковских технологий // Экономическая политика. 2012. № 4; Алехин Б.И. Кредитно-денежная политика. М.: ЮНИТИ-ДАНА, 2004. Гл. 1.

5 Sriram S.S. Survey of Recent Empirical Money Demand Studies // IMF Staff Papers. 2001. Vol. 47. № 3. P. 335.

6 Davidson P. Financial Markets, Money and the Real World. Cheltenham; Northampton, MA, 2002. P. 87.

7 Keynes J.M. The General Theory of Employment, Interest, and Money. Ch. 15, I // The University of Adelaide [Электронный ресурс]. URL: https://ebooks.adelaide. edu.au/k/keynes/john_maynard/k44g/complete.html\#chapter15 (дата обращения: 17.02.2015).

8 Ibid. 
9 Sriram S.S. Survey of Literature on Demand for Money: Theoretical and Empirical Work with Special Reference to Error-Correction Models // IMF Working Paper. 1999. Vol. 64. P. 8.

10 Ibid. P. 42.

11 Ibid. P. 28.

12 Ibid. P. 17; Sriram S.S. Survey of Recent Empirical Money Demand Studies. Table 1.

13 Keynes J.M. Op. cit. Ch. 15, I.

14 Статистика // Центральный банк Российской Федерации [Электронный pecypc]. URL: http://www.cbr.ru/statistics/ (дата обращения: 17.02.2015); Национальный счета // Федеральная служба государственной статистики [Электронный ресурс]. URL: http://www.gks.ru/wps/wcm/connect/rosstat_main/ rosstat/ru/statistics/accounts/ (дата обращения: 17.02.2015).

15 Friedman M. Op. cit.

16 Granger C.W.J., Newbold P. Spurious Regressions in Econometrics // Journal of Econometrics. 1974. Vol. 2. P. 111, 117.

17 Ibid.

18 Engle R.F., Granger C.W.J. Co-Integration and Error Correction: Representation, Estimation, and Testing // Econometrica. 1987. Vol. 55. № 2. P. 251-276.

19 Тесты на коинтеграцию пока распознают только долговременную линейную связь. Так что отсутствие коинтеграции не означает отсутствие долговременной связи вообще. Такая связь может быть нелинейной.

20 Магнус Я.Р., Катьшев П.К., Пересещкий А.А. Эконометрика. Начальный курс. М.: Дело, 2005. С. 252.

21 Johansen $S$. Statistical analysis of cointegration vectors // Journal of Economic Dynamics and Control. 1988. Vol. 12. № 2-3. P. 231-254; Johansen R., Juselius K. Testing structural hypothesis in multivariate cointegration of the PPP and the UIP for UK // Journal of Econometrics. 1992. Vol. 53. P. 211-244.

22 Популярная аналогия - подвыпивший хозяин, выгуливающий собаку без поводка. Расстояние между ними - величина случайная, но стационарная, хотя движение каждого есть случайное блуждание (Murray M.P. A Drunk and Her Dog: an Illustration of Cointegration and Error Correction // The American Statistician. February 1994. Vol. 48. № 1. P. 37).

23 Engle R.F., Granger C.W.J. Op. cit.

24 Магнус Я.Р., Катыпев П.К., Пересеикий А.А. Указ. соч. С. 253.

25 Ssekuma $R$. A Study of Cointegration Models with Applications: Master of Commerce Thesis. University of South Africa, 2011. P. 18. 